\title{
Revista Brasileira de Ensino de Ciência e Tecnologia
} ISSN: 1982-873X

\section{Filosofia e Ensino de Engenharia: a Relação Techné, Lógos e Métis}

\section{RESUMO}

José Aravena Reyes jose.aravena@ufif.edu.br

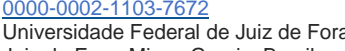
Juiz de Fora, Minas Gerais, Brasil.

\begin{abstract}
Este artigo apresenta um estudo sobre certos antecedentes etimológicos que fundamentam um solo epistemológico relevante para o ensino de Engenharia. Para tal, é apresentada a articulação dos termos gregos techné, lógos e métis para argumentar que a formação atual dos engenheiros enfatiza a formação científica, ao mesmo tempo em que dedica pouco esforço em desenvolver o pensamento inventivo, elemento chave para o desenvolvimento de competências para o processo criativo dos engenheiros.
\end{abstract}

PALAVRAS-CHAVE: Filosofia da engenharia. Filosofia da tecnologia. Educação de engenharia. Invenção. Métis. 


\section{INTRODUÇÃO}

O ensino de engenharia é pautado pela Lei de Diretrizes e Bases da Educação (LDB) que estabelece, para todos os sistemas de ensino, um conjunto de orientações básicas para a formação dos cidadãos no território brasileiro. No caso da formação de engenheiros, tais diretrizes se materializaram na resolução CNE/CES 11 de 2002 (MEC, 2002).

A tradicional instrumentalização técnica na formação do engenheiro foi alvo de muitas discussões ao longo do final do século XX, fato que levou diversos setores organizados da sociedade a participar dos debates que estimularam a reforma da educação implantada pela LDB e, consequentemente, um leque importante de atores sociais se engajou nas discussões que definiram as diretrizes para os cursos de engenharia. A Associação Brasileira de Ensino de Engenharia (ABENGE), por exemplo, promoveu várias discussões regionais envolvendo instituições de ensino de todo o país, cujas contribuições foram, na sua maioria, inseridas no texto final da resolução. Dentre essas contribuições se encontra a ideia de incorporar "novos conceitos e princípios relacionados com a elaboração do projeto curricular" que a partir desse momento deveriam ser utilizados pelos cursos de Engenharia. De certa forma, as diretrizes representaram um grande avanço ao promover um processo de formação por competências para que, entre outras finalidades, os engenheiros passassem a atuar de forma responsável e criativa no contexto vigente (CORDEIRO, QUEIRÓS \& BORGES, 2010: 125-126). Por outro lado, para além do texto final da normativa, o processo de construção social das diretrizes evidenciou os diversos interesses que existem na formação dos engenheiros, principalmente aqueles decorrentes da intenção de manter o omnipresente modo de produção do sistema capitalista.

Do texto do voto do relator escalado pelo CNE para emitir parecer em torno das diretrizes para engenharia, depreende-se que orientações normativas se fundamentam na necessidade de colocar no mundo do trabalho um novo engenheiro, cujo perfil será desenvolvido a partir de uma formação generalista, humanista, crítica e reflexiva, que permita dotá-lo da capacidade de absorver e desenvolver novas tecnologias, assim como de outras competências para atuar crítica e criativamente na identificação e resolução de problemas, considerando os seus aspectos éticos, políticos, econômicos, sociais, ambientais e culturais. Para tal, uma articulação consistente entre atividades e conteúdo deve ser demonstrada claramente (e previamente) no Projeto Pedagógico do Curso (MEC, 2001).

Nas diretrizes, surgem conceitos que, na discussão acadêmica, ainda são de difícil consenso (por exemplo, os termos técnico, tecnológico, engenharia, criativo, problemas), embora apareçam nesse documento, construindo fluidamente um sentido aparentemente claro e sem ambiguidades. Em primeira análise, tal situação pode ser generosamente entendida como uma abertura para explicitar o significado profundo desses termos no projeto pedagógico do curso. Porém, nem sempre isso é possível, porque, como descrito por (MITCHAM, 1998:29), os engenheiros "continuam a dar pouca atenção à sua formação em ciências humanas", arena onde se sustentam os princípios do projeto pedagógico de um curso de engenharia.

Com efeito, segundo Lopes (2016) ao fazer uma análise dos projetos pedagógicos dos cursos de engenharia de uma das universidades públicas 
brasileiras que aderiu ao processo de reformulação promovido pela Resolução 11 $\mathrm{CNE} / \mathrm{CES}$, se constatou que os projetos incorrem em problemas conceituais à luz dos referenciais estabelecidos pelos estudos em Ciência, Tecnologia e Sociedade (CTS). Tal confusão teria como fonte principal a confusão conceitual das próprias diretrizes da instituição em tela, que respaldam, inclusive, propostas que pregam uma compreensão da tecnologia como um fenômeno autônomo, que em função de um processo de evolução próprio, seria capaz de provocar mudanças sociais. Ou seja, segundo o autor da análise, os projetos analisados apresentam uma "visão instrumentalista da tecnociência, combinando a neutralidade com o controle humano" (LOPES, 2016: 27).

Para contextualizar a discussão explicitamente nas diretrizes da engenharia não é preciso ir tão longe: já nas suas primeiras linhas, as diretrizes explicitam que a formação do engenheiro deve ser baseada numa "sólida formação técnico científica" (MEC, 2002:1). Ora, embora o termo científico possa se considerar bastante delimitado como objeto de estudo, certamente, o termo técnico ou técnico-científico assume uma ambiguidade enorme, uma vez que o técnico, o tecnológico ou mesmo o tecnocientífico ainda não foi esgotado como assunto de estudo na perspectiva disciplinar da filosofia da engenharia, sendo claramente demonstrado pelos quantitativos que surgem ao se comparar publicações de estudos filosóficos em ciência, tecnologia e engenharia (SILVA, 2011).

As repercussões epistemológicas dessa condição são amplas e preocupantes, pois, embora muitos esforços sejam direcionados para tratar os problemas de ensino como problemas curriculares ou metodológicos (PINTO \& OLIVEIRA, 2012), na medida em que o solo epistemológico utilizado for pouco claro, há possibilidades que os projetos pedagógicos desenvolvidos sejam frágeis nos seus princípios, fato que resulta menos visível, quando observados a partir das suas aparentes formas metodológicas ou curriculares.

Os estudos em CTS formam um grande referencial para a análise macropolítica da tecnologia e, consequentemente, para o ensino de engenharia. Suas bases na Teoria Social fornecem um marco adequado para identificar, por exemplo, o grau de autonomia tecnológica que se está promovendo nos projetos pedagógicos dos cursos de engenharia através da adequação às normativas estabelecidas. Nesse sentido, não há dúvidas que as preocupações pela adoção de uma perspectiva determinista dura da tecnologia na formação dos engenheiros são uma pauta mais do que relevante para a crítica do respectivo processo educacional. Porém, o campo dos estudos em CTS é muito mais amplo que isso e inclui uma perspectiva histórica, sociológica e filosófica da tecnologia, dimensões que há muito dialogam com a filosofia da tecnologia e a nascente filosofia da engenharia (JARAMILLO, 2015).

A engenharia como campo autônomo de investigação filosófica vem reivindicando um espaço próprio, sem que isto signifique uma ruptura com o amplo esforço coletivo realizado dentro do campo de conhecimento dos estudos em CTS. Muito pelo contrário, a chamada virada empírica defendida pela escola de Delft na Holanda (KROES \& MEIJERS, 2001), propõe estabelecer um amplo espaço de diálogo para engenheiros, cientistas sociais, antropólogos e filósofos, com o intuito de elaborar uma perspectiva endógena da tecnologia, quer dizer, uma perspectiva que tenha como foco as práticas e os sujeitos associados ao projeto e produção daquilo que se denomina por engenharia. 
Vários autores apontam a necessidade dessa interação e propõem agendas coletivas. Uma dessas agendas é o Fórum de Filosofia da Tecnologia, promovido pela Sociedade para a Filosofia e a Tecnologia (The Society for Philosophy and Technology) , que reúne engenheiros, cientistas sociais, antropólogos e filósofos em uma única arena de reflexão.

No amplo contexto dos estudos conduzidos por essa comunidade, o sentido do técnico ou tecnológico utilizado corriqueiramente na engenharia, sequer se considera claro no campo filosófico e, por tal motivo, este trabalho se propõe a contribuir para um entendimento melhor desses termos, pois, à luz das inúmeras críticas aos resultados da ação técnica, parece ser urgente dar subsídios para novas interpretações em torno do processo formativo nas áreas técnicas e, especificamente, na formação de engenheiros, desta vez enfatizando a discussão filosófica.

O ponto de partida para este estudo é o trabalho Thinking Through Technology de Carl Mitcham, que entre outras preocupações, tratou das relações entre a filosofia da tecnologia e os estudos em CTS, afirmando inclusive, que ambos os campos se fortalecem mutuamente, por um lado, ao fornecer aos filósofos uma maior estrutura para desenvolver suas ideias (aquelas dos estudos em CTS) e, por outro, ao colocar a tecnologia em um contexto mais amplo (o filosófico) daquele dado pela comunidade CTS (MITCHAM, 1994: 273). Temas como a autonomia tecnológica desenvolvida por Winner (1977), a teoria crítica de Feenberg (1991) revisada em 2002-, a construção social dos sistemas técnicos desenvolvida por Bijker (BIJKER \& LAW, 1992), se bem colocam a tecnologia no campo da interação real com a sociedade, na filosofia da tecnologia esses autores são analisados desde particulares referenciais taxonômicos. Seja no escopo da ontologia, da fenomenologia ou da crítica, categorizações como a tradição humanista e engenheiril da tecnologia; a tecnologia como objeto, como conhecimento, como atividade e como volição, são territórios próprios do processo investigativo da filosofia da tecnologia e da engenharia, sendo que uma importante direção para definir ou conceituar tecnologia nesse campo é a abordagem etimológica (MITCHAM \& SCHATZBERG, 2009: 28).

Desta forma, e tomando como direção a abordagem etimológica, nas poucas páginas deste trabalho, as contribuições da crítica social da tecnologia pode ser analisada dentro do quadro taxonômico proposto por Mitcham (1898, 1994, 2009), assunto que foge aos limites de tempo e espaço deste estudo, pois a intenção presente é contribuir para novos entendimentos da engenharia somente desde a perspectiva filosófico-etimológica do termo tecnologia, fato que já provoca muitos reflexos na análise de elementos fundamentais que se utilizam para nortear o processo formativo dos engenheiros, alguns dos quais se pretendem abordar nas considerações finais deste trabalho.

Desta forma, o que se apresenta neste trabalho é uma perspectiva que potencializa as competências inventivas e transformadoras do engenheiro mediante uma análise da palavra grega techné (raiz etimológica tanto do termo técnica quanto do termo tecnologia) a qual por sua vez, se articula com outras duas palavras gregas: um lógos tradicional associado à dimensão racional da engenharia e uma esquecida métis, vinculada diretamente a uma inteligência astuciosa e engenhosa, cuja falta no perfil do egresso de engenharia é regularmente noticiada no setor produtivo. 
Pretende-se mostrar que há certo desequilíbrio na formação do engenheiro, ao colocar o lógos num papel dominante para o entendimento da técnica (como techné), em detrimento de uma métis que, para surgir fluidamente como inteligência astuciosa no exercício profissional, exige outros elementos do processo formativo que não aqueles denominados ambiguamente de técnicocientíficos ou puramente de científicos.

\section{Na busca de um discurso para a tecnologia}

Em 2006, a revista Techné da Sociedade de Filosofia e Tecnologia, publicou uma edição especial com textos de filosofia da tecnologia sob o título de "Durbin; na busca da síntese do discurso". Na opinião de Durbin, as controvérsias entre diferentes autores se resolvem através da síntese acumulativa dos seus conhecimentos, ainda quando ele mesmo anuncia antecipadamente que muitos filósofos da tecnologia têm contestado a ideia de que o acúmulo de conhecimentos das disciplinas científicas e suas ramificações no desenvolvimento tecnológico tenham, de fato, tornado o mundo melhor (DURBIN, 2006a:5).

A análise de Durbin é, segundo as suas próprias palavras, pluralista, no sentido de que não apresenta nem uma síntese dominante nem uma global. Portanto não é de estranhar que esse autor inclua dentro das suas reflexões três livros importantes, entre os quais se encontra Thinking Through Technology de Carl Mitcham (1994), ao qual dedica um capítulo inteiro da edição especial da revista .

Nesse capítulo, que Durbin intitula de "Uma Tentativa Prematura Para uma Síntese de Discurso", Mitcham é apresentado como um dos primeiros pensadores da tecnologia que elabora argumentos contra ou a favor a muitos filósofos da tecnologia. As controvérsias do seu livro principal (Thinking Through Technology) giram em torno da defesa que ele faz da chamada tradição humanista da filosofia da tecnologia (em detrimento da tradição engenheiril) e das categorias utilizadas para analisar a tecnologia. A saber: objetos, conhecimentos, atividades e volição.

Porém, Durbin aborda outros aspectos do trabalho de Mitcham. Em primeiro lugar, reconhece que o autor traz à reflexão, a engenharia e seus campos técnicos afins (diferente da maioria dos outros filósofos da tecnologia), fator muito relevante, inclusive porque uma forte crítica aos filósofos da tecnologia é que eles não incluem de forma satisfatória, análises sobre o que os profissionais técnicos fazem, embora constantemente argumentem que trabalham para "a melhoria das condições humanas" (DURBIN, 2006b:22).

Além de levantar outros pontos relevantes, como são os argumentos de Mitcham em relação à supremacia da tradição humanista da filosofia da tecnologia e da sua aparentemente estranha atitude para com a ética e a política da tecnologia, Durbin considera o esforço de Mitcham valioso no sentido de ser um resumo amplo de algumas das maiores contribuições à filosofia da tecnologia ou também por ser um completo resumo do que engenheiros e especialistas técnicos falam acerca do seu trabalho e dos seus produtos. Em resumo, Durbin considera que o trabalho de Mitcham representa um guia para desenvolver uma atitude em relação à tecnologia moderna e que seu trabalho deve ser entendido como uma referência conceitual para pensar a tecnologia desde dentro dela.

Tudo leva a concordar com a análise de Durbin em especial por uma apreciação específica: que o trabalho de Mitcham é precioso para aproximar a 
engenharia em direção da filosofia. De fato o segundo título do livro de Mitcham é exatamente The Path Beetwen Engineering and Philosophy.

A leitura de Durbin é ampla e consistente. Porém, para os objetivos deste trabalho há outro assunto muito importante a ser tratado (não destacado por Durbin) que também é abordado em outros textos de Mitcham e que pode representar um solo epistemológico relevante para avançar em uma direção da compreensão da filosofia da engenharia e dos condicionamentos epistemológicos que levam ao entendimento dominante do ensino de engenharia .

Trata-se da escolha de Mitcham em abordar o termo tecnologia e não o termo técnica para explicar as suas percepções sobre o universo técnico e, consequentemente, sobre o universo do ensino de engenharia.

\section{A Techné nos trabalhos de Mitcham}

No livro que leva por título "Que é a Filosofia da Tecnologia" (MITCHAM, 1989), a perspectiva adotada por esse autor, embora seja uma das maiores contribuições recentes para o tema, não esclarece suficientemente porque é feita a escolha de usar o termo tecnologia e não o termo técnica. No prefácio do livro, Mitcham (1989) esclarece somente que os termos técnica e tecnologia possuem significados diferentes e a ciência passa a ter um papel especial nas definições adotadas pelo autor. Nesse livro, a tecnologia (diferentemente de técnica) é entendida como os afazeres da ciência moderna (posteriormente concebida como a forma do atual paradigma da produção dos artefatos), enquanto a técnica, por sua vez, é considerada a forma primordial da ação humana, presente na tecnologia, porém, num contexto mais geral.

Como a tecnologia inclui a técnica como a sua forma primordial, segundo Mitcham seria a tecnologia o conceito mais abrangente, no sentido de que esta última contempla implicitamente a técnica e explicitamente aquilo que é característico da tecnologia. Assim, para ele, "a filosofia da tecnologia é mais geral e inclui a filosofia da técnica" (1989:14).

Essa direção de entendimento é reforçada em Thinking through Technology, onde o autor escreve o capítulo Philosophical Questions about Techné (Mitcham, 1994:114) para tratar das relações entre o termo tecnologia (e não o termo técnica) e o termo grego techné. O tema é recuperado novamente no livro Philosophy of Technology and Engineering Sciences, no capítulo intitulado Defining Technology and Engineering Sciences (MEJERS, 2009), onde Mitcham \& Schatzberg (2009:27) argumentam que para avançar na conceituação do tema, podem-se utilizar cinco abordagens: etimológica, essencial, prescritiva, linguística e pragmática.

No caso do argumento etimológico, Mitcham, para chegar a elaborar sua conceituação de ciência(s) da engenharia, utiliza e se orienta pelo termo tecnologia, para o qual elabora toda uma análise etimológica, citando principalmente, Sócrates, Platão e Aristóteles.

O primeiro Platão, segundo Mitcham, teria adotado como ideia de definição da técnica que ela seria algo co-extensivo àquelas atividades humanas sobre as quais poderia se falar ou raciocinar (inclusive ensinar). Já o Platão tardio, faz uma classificação da techné de acordo com o tipo de conhecimento a ser utilizado: 
prático empírico (a techné da música ou a medicina) ou exato e preciso (como a carpintaria, que envolvia medições geométricas), sendo estas últimas "mais" techné que as primeiras (MITCHAM \& SCHATZBERG; 2009:33).

Embora Sócrates e Platão, resultem interessantes para o trabalho etimológico, também é relevante que, tanto o primeiro quanto o segundo recebem críticas em relação à autoria ou teor dos seus postulados. No caso de Sócrates, por exemplo, chega a ser dura a crítica de Nietzsche descrita no Crepúsculo dos ídolos (Nietzsche, 2000) onde o filósofo grego é tratado como um homem cansado da vida e onde, tanto Sócrates quanto Platão, são referidos como anti-gregos, no sentido de se colocarem de frente à vida de forma negativa, tirando dela toda a sua vitalidade para referenciá-la a juízos de valor que "nunca podem ser em última instancia verdadeiros" e onde mediante uma técnica (a dialética) deixa-se que o dialético delegue ao seu adversário "a necessidade de demonstrar que não é um idiota". Com isso, podemos pensar que, embora o pensamento desses dois primeiros filósofos gregos possa contribuir para o entendimento do espírito da época, as suas opiniões podem ter sido conduzidas, mais que pelo espírito de representar a época, pela necessidade de validar uma razão salvadora, como descreve Nietzsche, perante o "fato de ninguém mais se assenhorear de si" e "de os instintos se arremeterem uns contra os outros". Todos os diálogos (textos de referência utilizados por Mitcham), de certa forma ilustram a maiêutica de um Sócrates que não diz muito a não ser o necessário ao uso do seu método. Por outro lado, embora Mitcham não elabore a questão da techné a partir, por exemplo, dos pré-socráticos, ele inclui Aristóteles, que nas suas obras sintetiza e reposiciona, de acordo com sua filosofia, o pensamento de Sócrates e de Platão e de toda a tradição do pensamento grego. Portanto, para compreender a techné grega de Mitcham pode-se começar pela análise que ele fez sobre a techné de Aristóteles.

Mitcham sintetiza o pensamento desses três filósofos gregos para afirmar que talvez, o limitado papel concedido ao lógos da techné, explique, tanto em Platão como em Aristóteles, a ausência do termo grego technologia, com ressalvas para o aparecimento desse termo na Retórica de Aristóteles, onde uma forma dessa palavra aparece quatro vezes, dando origem, segundo o autor, ao entendimento da tecnologia como tratado das artes da linguagem (MITCHAM \& SCHATZBERG; 2009:35).

Certamente se pode considerar que as contribuições para constituir o entendimento do que Aristóteles elaborou da techné podem vir de muitos textos (como a Retórica citada no parágrafo anterior), porém, no Livro I da Metafísica, Aristóteles assinala que "a diferença entre a arte a ciência e as demais atividades mentais afins foi indicada na Ética" (ARISTÓTELES, 2012:43). Considerando que o termo grego techné se traduz para o português também como arte, e sem entrar no mérito das conclusões sobre a origem ou uso de uma forma inicial do termo grego technologia, a perspectiva de Mitcham parece se orientar para um logos ausente (portanto necessário) na techné de Platão e Aristóteles, e embora ele mesmo considere que não há antecedentes sobre um uso contínuo da palavra tecnologia "que unam o termo grego technologia com os atuais significados" do termo, o autor relata que Jacob Bigellow teria adotado no inglês uma palavra (tecnologia) que se encontrava nos velhos dicionários para incluir "uma conta... dos princípios, processos e nomenclaturas das artes mais cultas, em particular, as que implicam aplicações da ciência" (MITCHAM \& SCHATZBERG; 2009:36). 
Também se pode inferir que a necessidade do logos grego, para Mitcham, se torna relevante porque permite sustentar a premissa da importância do logos da ciência moderna na caracterização do termo tecnologia, na sua acepção atual. De fato, não há por que discordar disso, mas certamente o logos grego é muito mais do que um instrumento de afirmação para a epísteme, e nesse sentido Aristóteles foi muito claro.

Portanto, não é um argumento menor o fato de estar presente no pensamento de Mitcham a ideia de um papel limitado do logos na techné grega. 0 fato concreto é que tanto logos quanto techné foram palavras muito importantes para os gregos e embora ambas as palavras tenham uma articulação importante para os gregos, não são as únicas palavras importantes para avançar em direção de uma filosofia da engenharia.

O que se assume implicitamente neste trabalho é que a técnica atravessa o humano e se foi separada ou colocada para fora do homem, tal cisão parece artificial, devendo-se identificar os cortes epistemológicos e sociais que deram origem a essa leitura. Por exemplo, mais do que separar techné e lógos, a análise da filosofia grega deste trabalho se articula através da relação que existe entre os termos techné, lógos e métis, pois desta forma o significado do termo técnica passa a ter um teor bastante ilustrativo para as tarefas a serem empreendidas numa educação de engenharia.

\section{Métis, Logos e Techné à luz da filosofia grega}

Marilena Chauí coloca que o valor dado pelos gregos ao termo techné está intimamente associado ao surgimento da democracia na Grécia. Segundo a autora, para desfazer o poder das famílias aristocráticas gregas (que em função do seu poder e das suas riquezas governaram de forma despótica durante muitos séculos) Sólon, um estadista de Atenas antecessor de Péricles, estimulou o desenvolvimento e enriquecimento dos artesãos, patrocinando as técnicas e criando honrarias para os ofícios (CHAUí, 2002:141). No pensamento grego, especialmente para os atenienses, a techné era um valioso "saber prático obtido pela experiência e realizado por habilidade" em torno de toda atividade humana produtiva, quer dizer, em torno da poiesis, termo que representa aquela ação que visa um agente externo ao homem.

Chauí alerta para outros termos gregos que se articulam com a techné, como é o caso da dynamis, que representa a aptidão potencial da matéria a ser transformada pela técnica a partir de um eidos, ou seja, de uma forma, a qual será materializada num érgon, que corresponde à obra, sendo esta uma coisa (p.e. uma mesa) ou uma ação (p.e. a ação médica).

A techné não seria invenção e sim produção externa ao agente que o produz, porém Chauí descreve dois tipos fundamentais de técnicos: o architecton, que conhece os princípios racionais de uma techné e o mechanopoiós, que possui o conhecimento prático e inventivo sob a fabricação e funcionamento de uma techné. Os artesãos, simples operários do processo produtivo, que não conheciam nem as causas nem os efeitos de uma techné, são excluídos de tudo esse universo criativo. Eles geralmente eram escravos ou homens livres pobres, membros de uma estrutura social típica da época, situação que alimentou um entendimento 
pejorativo das técnicas manuais por parte de diversos pensadores da técnica ao longo da história.

Chauí destaca no seu livro outros dois termos extremamente próximos ao que se entende por techné e que chegam a se confundir com ela: por um lado o termo lógos, com o qual se estabelece um vínculo entre a techné e o processo racional de identificação, escolha, divisão ou agrupamento daquilo que está disposto na natureza, mas que não é a própria natureza (digamos, o artificial); e por outro lado, o termo métis, relacionado a um pensamento engenhoso (prático e eficaz) que opera no devir.

O lógos, à luz do verbo legein, é apresentado como um procedimento fundamental da techné e não puramente restrito ao pensar ou dizer como geralmente é entendido. Segundo Chauí, foi Castoriadis que estabeleceu esta distinção destacando que os pensadores gregos pensavam e falavam segundo um dissói logói, quer dizer, segundo um procedimento de divisão em contrários. De forma similar, segundo Castoriadis, o termo techné, à luz do verbo teukkein, operaria no mesmo modelo dissói logói, reunindo, juntando, fabricando, por um lado, e escolhendo, distinguindo, separando, por outro.

\title{
Como aponta Chauí:
}

\begin{abstract}
A oposição que legéin estabelece entre ser e não-ser aparece em teukkein e em tekhné como oposição entre possível e impossível, factível e não-factível, útil e nocivo; e a oposição entre uno e múltiplo aparece como oposição entre obra e caos, ação racional e acaso.(CHAUÍ, 1994:144)
\end{abstract}

Para Galimberti, a techné de Platão se orienta para uma análise hierárquica em relação à política (a "técnica régia"). Se por um lado para Platão as técnicas são especializadas (assim como a sua execução e, portanto relacionáveis num sistema social de divisão de tarefas, isto quer dizer, reguláveis), elas exigem uma técnica maior, uma razão que possa medir tais técnicas em função do seu uso e não da sua produção, dado que o produzir grego em Platão era inferior e devia ser remetido a outras técnicas, digamos superiores, que explicam as primeiras, e dentre as quais a política é a maior por ser a medida (no uso) de todas as outras técnicas (GALIMBERTI, 2006:295).

Daqui pode-se inferir que o logos de Platão tende à razão e à ideia por uma questão epistemológica primeira: a necessidade de explicar o que é o homem (eidética) e não à maneira de Nietzsche que é como -o homem- veio ao mundo (genealogia). O homem de Platão é virtuoso, e desenvolve suas virtudes mediante o conhecimento justo e verdadeiro, que é o logos defendido por ele.

O caso de Aristóteles é um pouco diferente, pois embora não tenha essa preocupação metodológica, coincide com Platão em que a política é a maior das ciências práticas. De fato, para Aristóteles, a filosofia (que é a totalidade do saber) envolve as ciências teoréticas e as ciências práticas e é nesta última que está muito bem caracterizada a técnica como techné oriunda de uma poiesis, porém remetida ainda a um lugar inferior em relação à outra forma, a práxis, todas as duas representando diferentes domínios da ação humana. A primeira definida por um fim externo a ela (a obra) e a outra sendo um fim em si mesmo.

O logos aristotélico é múltiplo, não eidético, capaz de explicar o mundo sensível, quer dizer o mundo das ações humanas, através do qual é possível a 
criação de unidades inteligíveis, dando outro horizonte epistemológico ao logos explicativo da realidade: o de um instrumento (o discurso) para o reto raciocínio.

Na Ética a Nicômano, Aristóteles (2013) faz uma detalhada análise da techné. Para começar esclarecendo um cuidado desta em relação à exatidão que tanto agrada a Platão:

não devemos pretender uma exatidão igual em todos os departamentos do estudo ... Nem tampouco devemos nós em todos os objetos de estudo exigir igualmente uma explicação da razão do porquê as coisas são o que são; em alguns casos, será suficiente que o fato delas serem o que são esteja satisfatoriamente estabelecido (ARISTÓTELES, 2013:51-1098b1)

Em outras palavras, no próprio procedimento de Aristóteles, existe a possibilidade de inexatidão. Se "o carpinteiro e o geômetra procuram o ângulo reto", e se o primeiro "se contenta com a aproximação capaz de satisfazer o propósito de seu trabalho" é porque há na ação prática uma condição de realização que está além da necessidade da medida.

Há uma dimensão do conhecimento da alma que, "embora irracional, participa do princípio racional” (Aristóteles, 2013:64-1012.b10). Esta componente não é exatamente a loucura nem nada similar, senão algo que não pode ser explicado pela racionalidade atribuída à matemática; ela tem "o sentido que emprestamos ao acatamento do 'racional' quando falamos em dar atenção". Quer dizer, não é a medida de proporção da matemática nem o logos da racionalidade teorética ou científica que Aristóteles associa como um dos traços da techné, senão um logos que pondera, que usa uma mediana relativa aos seres humanos, quer dizer, um logos próprio da vida prática; a justa razão da ação humana, que delibera não sobre a incomensurabilidade da diagonal e o lado de um quadrado (ARISTÓTELES, 2013:94-1112.b20) senão "sobre coisas que estão sobre o nosso controle e que são atingíveis pela ação" e que nem sempre produzem o mesmo resultado, como na medicina, nos negócios ou na navegação, todas elas entendidas como uma sorte de techné no pensamento grego.

Também Aristóteles esclarece que a deliberação é sobre meios (e não sobre fins) e sobre a possibilidade dos meios realizarem o fim pretendido. Portanto, no exercício de uma techné:

A questão num momento é saber quais ferramentas usar e, num outro, como usá-las; similarmente, em outras esferas, temos que considerar, por vezes, que meios empregar e, outras vezes, como exatamente determinados meios devem ser empregados (ARISTÓTELES, 2013:96-1112b.25).

Aparentemente, a incerteza encontrada na techné é inerente à sua condição de conhecimento e ação prática e não há nenhuma necessidade em traduzir tais incertezas em certezas. É necessário saber deliberar nesse instável contexto que trará, mediante a escolha, o fim da indagação e o princípio ou fundamento da ação "para a parte dominante de si mesmo, pois é essa parte que escolhe" (ARISTÓTELES, 2013:97-1113.a1).

Desta forma, na vida prática (e portanto na techné) há uma justa razão (um logos) entre o excesso e a deficiência.

Dentre as virtudes da alma, Aristóteles faz uma diferenciação entre aquelas que são oriundas do caráter (morais) e as que são do intelecto (psique). A alma 
tem duas faculdades racionais: uma mediante a qual se pode especular sobre princípios invariáveis e a outra serve para especular sobre coisas que admitem variação, a primeira chamada de faculdade científica e a segunda de faculdade calculadora.

O objeto do conhecimento científico é relativo a coisas invariáveis, ou seja, que existem necessariamente, e como tal, devem ser demonstradas e sua demonstração deve convencer por sua exatidão. Já no caso das coisas variáveis, onde devem se incluir tanto a ação realizada como a as coisas criadas (como a construção de uma casa), também existe um processo de verdadeiro raciocínio.

Com isto Aristóteles esta delimitando o pensamento técnico. Toda arte (techné) se ocupa:

\footnotetext{
em trazer alguma coisa à existência, e dedicar-se a uma arte significa estudar como trazer ao existir uma coisa que é possível existir ou não, a causa eficiente da qual estando no criador e não na coisa criada, pois a arte não se ocupa com coisas que existem ou passam a existir (vem a ser) necessariamente ou eficientes em si mesmas. Mas como criar e fazer são distintos, infere-se que a arte, sendo concernente ao criar, não concerne ao fazer. E num certo sentido a arte se ocupa dos mesmos objetos da sorte ... Arte, portanto, como dissemos, é uma qualidade racional concernente ao criar, segundo um processo verdadeiro de raciocínio... (ARISTÓTELES, 2013:183-1140.a10)
}

Aristóteles aqui está nos alertando de um raciocínio característico do pensamento técnico, um processo que é verdadeiro porque existe e não porque existe necessariamente como os objetos da faculdade científica da alma. Este logos, característico da techné, então é um logos criador, dentro do universo do variável e que opera a partir da deliberação.

Aparentemente esta descrição já fornece indícios para pensar de forma mais ampla a técnica, mas a techné não está suficientemente explicitada somente a partir do logos. Como descrito por Chauí, há de se relacionar também a techné com a métis.

Chauí cita os trabalhos de Vernant para explicar a métis, caracterizando-a como uma inteligência prática ou um dom para "encontrar um caminho onde parece não haver nenhum" (CHAUÍ, 1994:144). Suas formas manifestas passam pelo engenho e a astúcia (entre outras) e serviam para descrever o perfil do capitão naval, o estrategista, o político, o médico e o sofista, todos os quais eram dotados de "engenho e arte" (CHAUÍ, 1994:145).

Já Detienne \& Vernant (2008:17) apontam que Henri Jeanmarie reabriu o debate da métis ao argumentar que a deusa fora esquecida de grande parte dos relatos dos textos gregos, mas que ela possui um papel fundamental porque designa uma inteligência que se exerce sobre os planos mais diversos, mas sempre onde o acento é posto sobre a eficácia prática, a procura do êxito em um domínio da ação.

A métis merece especial atenção, pois também está fortemente associada ao nascimento da techné humana através do mito do deus grego Prometeu.

Segundo esse mito, Prometeu (que significa aquele que pensa antes) ao ver que na distribuição das qualidades dos seres vivos o homem ficou sem receber nada, a pedido do seu irmão Epimeteu (que significa aquele que pensa depois) 
enganou e roubou de Zeus o fogo e o passou aos homens a fim de que estes não ficassem em desvantagem perante os outros animais.

É importante entender que Prometeu, tem como uma das suas características mais marcantes a inteligência astuciosa de Métis, primeira esposa de Zeus, engolida por este a conselho de Gáia e Urano para que não exista ninguém mais astuto que o Rei dos deuses.

Segundo a mitologia grega, aos homens foi-lhes dado o fogo que era dos deuses (fogo divino), que, ao ser apropriado por eles, deixa de ser um fogo divino e passa a ser fogo técnico, no sentido do termo grego techné. Assim, Prometeu, criador que cria através do intelecto, que pensa antes, que carrega a astúcia em si, coloca a técnica como elemento constitutivo dos homens.

Em uma nota sobre uma passagem de Epicteto que descreve a rejeição de encargos contrários à natureza, (DINUCCI, 2012:38-39) se refere ao logos Heraclitiano como o "princípio diretor do real... lei que orienta o surgimento, o desaparecimento e as transformações de todas as coisas do mundo e também princípio físico da realidade (o fogo)". A partir disso pode-se entender que o fogo divino, além de representar a técnica, se coloca como princípio fundamental da realidade que o homem percebe na sua relação com a natureza.

Como para Vernant os mitos são narrativas que "contribuem para moldar o quadro mental em que os gregos são muito naturalmente levados a imaginar o divino" (VERNANT, 2006:15) e "é pela voz dos poetas que o mundo dos deuses... é apresentado aos humanos", ou como os deuses gregos "não são pessoas mas Potências... eles constituem uma raça que ... encarna não o absoluto ou o infinito mas a plenitude dos valores que importam na existência nesta terra" (Vernant, 2006:9), no mito de Prometeu encontramos mais do que o relato de um episódio da vida dos deuses gregos. Nele se pode situar o entendimento que foi elaborado nessa época de uma parte importante da existência humana: a técnica.

Prometeu e Zeus estão imbrincados desde o nascimento dos homens, ou melhor, desde o momento da separação dos homens do mundo dos deuses.

Com efeito. Instituído o sacrifício que demarcaria os limites de cada raça, Prometeu, tentando favorecer os homens, engana a Zeus oferecendo-Ihe sob uma falsa imagem apetitosa os ossos do boi-oferenda, dando aos homens as partes mais saborosas. Zeus, sem cair na armadilha, escolhe os ossos brancos e deixa a carne para os homens:

"Ao comerem a carne, os humanos assinam sua sentença de morte. Dominados pela lei do ventre, doravante irão comportar-se como todos os animais que povoam a terra... se têm imperiosa necessidade de alimento, é que sua fome jamais mitigada, sempre renascente, é a marca de uma criatura condenada à fadiga, ao envelhecimento e a morte. Contentando-se com a fumaça dos ossos, vivendo de odores e de perfumes, os deuses demonstram pertencer a uma raça cuja natureza é inteiramente diferente da dos homens. Eles são os Imortais, os sempre vivos, eternamente jovens..." (VERNANT, 2006:63).

Não satisfeito ainda, Zeus priva os humanos do fogo celeste, tendo como consequência que os homens "deverão devorar a carne crua" como todos os animais. Porém, é nesse momento que Prometeu novamente investe contra Zeus para defender os homens, furtando uma semente do fogo e levando-a para a terra, 
inaugurando assim o fogo técnico, "mais frágil e mortal, que é preciso conservar, preservar e nutrir alimentando-o para que não se apague” (VERNANT, 2006:64).

Prometeu Acorrentado é um poema, onde Ésquilo que conta as vicissitudes de um Prometeu que é punido por Zeus por ter furtado o fogo divino para dá-lo aos homens.

Já na sua primeira intervenção, Prometeu argumenta:

Os benefícios que fiz aos mortais atraíram-me este rigor. Apoderei-me do fogo, em sua fonte primitiva; ocultei-o no cabo de uma férula, e ele tornouse para os homens a fonte de todas as artes e um recurso fecundo (ÉSQUILO, 2005:13)

tudo isso por que amei os mortais... (ÉSQUILO, 2005:14)

Zeus, depois de instalado no trono do seu pai (Cronos) tratou de fortificar seu império ao mesmo tempo em que pensava aniquilar os mortais. É Prometeu que se compadece e intercede pelos mortais permitindo que estes tenham esperança no futuro e participação do fogo celeste, descrito por Prometeu (o fogo) como o mestre do qual "aprenderão muitas ciências e artes" (ÉSQUILO, 2005:21).

Prometeu torna os homens "inventivos e engenhosos", dado que antes "eles viam, mas viam mal; e ouviam, mas não compreendiam".

Tanto amou o benfeitor da humanidade aos mortais que no poema de Ésquilo são citadas várias das criações técnicas com as quais Prometeu presenteou aos homens para ilustrar como o deus os ajudou:

\begin{abstract}
Sem raciocinar, agiam ao acaso, até o momento em que eu lhes chamei a atenção para o nascimento e ocaso dos astros. Inventei para eles a mais bela ciência, a dos números; formei o sistema do alfabeto, e fixei a memória, a mãe das ciências, a alma da vida. Fui o primeiro que prendi os animais sob o jugo, a fim de que, submissos à vontade dos homens, Ihes servissem nos trabalhos pesados ... ninguém mais senão eu, inventou esses navios que singram os mares, veículos alados dos marinheiros
\end{abstract}

..

ainda mais admirareis o valor das artes e indústrias que dei aos mortais. Antes de mim ... quando atacados por qualquer enfermidade, nenhum socorro para eles havia, quer em alimentos, quer em poções, bálsamos ou medicamentos ... em suma: todas as artes e conhecimentos que os homens possuem são devidos a Prometeu (ÉSQUILO, 2005:32-34)

O erro de Epimeteu na distribuição das qualidades dos seres vivos foi reparado por Prometeu, mas lhe custou a ira de Zeus: os homens ganharam o fogo; Prometeu, as correntes.

Na Teogonia, Métis é a deusa que "sabe mais coisas que qualquer deus ou homem mortal" (HESIODO, 1979:49) enquanto que para Prometeu "o futuro não tem segredos" (ÉSQUILO 2005:13). Possuidor de um grande segredo de Zeus, Prometeu é detentor de uma grande métis que logo voltará a confrontar com a métis do Rei para sair do seu infortúnio. 
Detienne \& Vernant consideram que Prometeu (o previdente) tem o lugar e desempenha o papel que Hesíodo assinala à deusa Métis, quer dizer, o papel de uma forma de inteligência artificiosa, que por sua vez está associada, no aparecimento da raça humana, aos objetos técnicos, quer dizer, objetos produzidos a partir de uma inteligência prática e astuciosa.

A métis remonta aos textos de Homero. No episódio dos jogos, Antíloco, em notada desvantagem triunfa sobre Nestor (mais forte) mediante procedimentos de uma ordem diferente da força: uma astúcia que é característica da métis. 0 episódio dos jogos se passa numa corrida de cavalos, num terreno móvel, de uma situação incerta e ambígua, que revelam um Antíloco altamente "concentrado num presente do qual nada Ihe escapa, mais tenso em relação ao futuro, do qual ele antecipadamente maquinou diversos aspectos, enriquecido pela experiência acumulada no passado" (DETIENNE \& VERNANT, 2008:21).

A métis também não é uma, mas múltipla e diversa, como no caso de Ulisses, que é chamado o herói polymetis, quer dizer aquele que possui astúcias variadas, pois nunca Ihe faltam expedientes para livrar-se de todo tipo de embaraço.

O homem de métis tem supremacia sobre a força, age no tempo do relâmpago e possui a flexibilidade necessária para lidar com realidades que nunca cessam de se modificar.

Para exemplificar melhor esta dimensão da astúcia, Detienne \& Vernant (2008) descrevem a presença da métis tanto no polvo quanto na raposa, dois animais de extrema importância no pensamento grego por serem dotados de uma astúcia superior ao resto dos animais, caracterizada principalmente pelas qualidades de polimorfismo e polivalência com as quais são capazes de dominar realidades fluidas e móveis.

Nos tratados de pesca e caça de Opiano a métis também é relacionada com a techné, quando, por exemplo, "os polvos se confundem com a rocha sobre a qual se apoiam" (DETIENNE \& VERNANT, 2008:33) ou quando a raposa se finge de morta, e brilha numa brusca virada na qual se apodera dos ouriços (DETIENNE \& VERNANT, 2008,41). Quer dizer, é esse tipo de astúcia que permite a esses animais desenvolver sua tão sofisticada techné.

Detienne \& Vernant relacionam ainda esta métis característica do polvo e da raposa com comportamentos humanos que toda a cultura grega reconhece: o homem dos mil artifícios (polýtropos), dos instantes e das mudanças (ephémeros) e dos liames (polýplokos). O homem que possui essas características é o sofista que sabe torcer os discursos e os artifícios.

A métis de Detienne \& Vernant "Pelos indícios e pelos comportamentos que a caracterizam, os domínios em que ela se exercita, os estratagemas que ela emprega para inverter as regras do jogo na prova de força": tipo particular de inteligência que, em lugar de contemplar as essências imutáveis, encontra-se diretamente implicado nas dificuldades da prática, com todas as suas probabilidades, confrontando com um universo de forças hostis, desorientadoras, porque são sempre móveis e ambíguas. Inteligência em obra no futuro, em situação de luta, a métis reveste a forma de uma potência de confronto, utilizando qualidades intelectuais -prudência, perspicácia, prontidão e penetração de espírito, artimanhas ou mesmo mentira- mas estas qualidades desempenham como tantos sortilégios dos 
quais ela disporia para opor à força bruta as armas que são seu apanágio: a inapreensibilidade e a duplicidade. Como a água corrente, o ser dotado de métis desliza entre os dedos de seu adversário; por força da flexibilidade ele se torna polimórfico; como armadilha, ele é também o contrário do que aparece: ambíguo, invertido, ele age por viradas (DETIENNE \& VERNANT, 2008:)

Esta síntese é extremamente relevante, pois embora o lógos na techné possa também representar uma inteligência ou um tipo de pensamento vizinho à verdadeira razão (quase uma epísteme), forçando-a a procurar seu sentido de ser na racionalidade (como aparentemente parece ser o intuito de Mitcham), não é menos válido que o homem ao produzir-se (por exemplo, através da tragédia grega) pode até atualizar uma dimensão da natureza (physis) que modifica tudo o que se considerava incluído nela antes dessa mudança, mostrando que esse lógos não se ergue num contexto estável nem como condição prévia ou externa à techné: sem dúvidas seus limites são incertos e pode-se pensar mais numa sorte de emaranhado do que em relações, onde métis e o lógos se estabelecem como elementos próprios do pensamento técnico e não como duas entidades ontologicamente separadas que se relacionam exteriormente com a techné.

De forma diferente, a techné analisada à luz da filosofia grega a partir de Platão e Aristóteles pode bem servir para reforçar a ideia de que a techné se orienta com um tipo de pensamento de conotações científicas ou de um processo de busca da verdade.

Para Aristóteles, techné é arte e epísteme é ciência. Ambos os termos definem dois modos diferentes do homem possuir a verdade. A epísteme ou conhecimento científico seria um tipo de conhecimento demonstrativo do objeto com que uma particular ciência se ocupa das causas e fundamentos primeiros (em termos universais e necessários) desse objeto. Mais do que se referir a um método específico, Aristóteles lança mão da relação entre o variável e o invariável para diferenciar a epísteme da techné.

O invariável pode ser apreendido, refletido e erguido sobre uma base sólida e racional, enquanto o variável só pode ser apreendido como um saber singular. A elevação desse conhecimento singular (porém consistente) ao patamar de necessário e universal seria o movimento de aperfeiçoamento de uma arte para uma ciência. Mas não há esse procedimento hierárquico, pois para Aristóteles a arte encontra-se exatamente no domínio do produzir e não necessariamente como um processo menor em relação ao conhecimento científico, pois a arte se ocupa em "inventar e em considerar as maneiras de produzir alguma coisa que tanto pode ser como não ser" e o conhecimento científico "um estado que nos torna capazes de demonstrar"; "um juízo sobre coisas universais e necessárias".

Desta forma, a epísteme -ou conhecimento científico- seria de ordem explicativa e a techné -como arte ou técnica- seria da ordem inventiva ou produtiva.

$\mathrm{Na}$ Ética a Nicômaco, Aristóteles descreve a arquitetura como uma techné, ou seja, como uma "capacidade de produzir que envolve o reto raciocínio". Entendese que o reto raciocínio de Aristóteles revela a existência de um conhecimento depurado e consistente sobre o objeto a ser produzido, mas não necessariamente um conhecimento demonstrativo que esgota seu objeto de forma universal. De fato, para Aristóteles, o objeto da arte arquitetônica é algo cuja "origem está no 
que se produz e não no que é produzido". A partir disso podemos pensar que, apesar das distinções feitas entre techné e epísteme, para Aristóteles a techné não se preocupa com a condição ontológica de um dado objeto e sim com seu processo de invenção ou produção.

\section{Considerações Finais}

Similar à arquitetura, a engenharia possui sua techné característica. Dotada de racionalidade (lógos) e inventividade (métis), a dimensão técnica da engenharia expõe uma condição de existência produtiva em relação à vida. Desta forma, em relação ao exposto neste trabalho, o termo tecnologia pareceria possuir uma redundância no lógos (como também seria o caso de uma "tecnometia" ter ênfase numa métis), sendo que isto não representa uma negação das relações que esse termo manifestamente possui na atualidade com a ciência moderna, mas sim um cuidado que deve ser considerado na elaboração dos currículos de ensino dos cursos de engenharia.

Este cuidado é necessário uma vez que a engenharia não se esgota na condição da previsão estável dos invariantes científicos. A própria techné grega evidencia que a engenharia possui também uma relação ampla com o devir e o invariável, fato que por sua vez, é bastante conhecido na vida prática dos engenheiros, onde constantemente surgem procedimentos engenhosos criados para lidar com o impreciso ou instável. Mesmo quando na abordagem diária das situações profissionais eles tentam fazer do modelo estável da realidade a própria realidade, esta mesma dá sinais de esgotamento, mostrando sua improcedência na medida em que se força uma solução universal para um caso particular que não está plenamente contemplado no referido modelo.

A engenharia é amplamente entendida em função da resolução de problemas. Por exemplo, uma definição comum encontrada na literatura aponta que "a engenharia moderna é aquela que se caracteriza por uma forte aplicação de conhecimentos científicos à solução de problemas" (BAZZO \& PEREIRA, 2006). Tal afirmação se traduz, no ensino de engenharia, abordando as tarefas de ensino em termos de deficiências ou ausências metodológicas (PINTO \& OLIVEIRA, 2012) as quais, por sua vez, se equacionam mediante o uso de abordagens metodológicas tais como o ensino por problemas. Porém, não é a condição ontológica do problema que ganha centralidade no ensino baseado em problemas. É a aplicação do conteúdo programático que nessa abordagem metodológica se organiza em torno de um enunciado cujas condições de variabilidade estão sobre controle. Ou seja, um campo controlado para o desenvolvimento de uma racionalidade (lógos) pré-estabelecida de aplicação de conteúdos, em contraposição a um cenário menos previsível que possa envolver a invenção (métis) assim como as abordagens de resolução desses problemas (ARAVENA-REYES, 2014a).

$\mathrm{Na}$ engenharia, a perspectiva dominante da resolução de problemas tem afetado alguns dos seus domínios disciplinares. Na área de Engenharia de Sistemas, por exemplo, o nascimento da abordagem "soft systems" no final dos anos 60 , foi uma das respostas encontradas à dominante abordagem funcionalista de sistemas da época, que muitas vezes se restringia a aplicar diretamente os princípios epistemológicos ou métodos das ciências naturais para lidar com os problemas de engenharia, onde se verificava que tais problemas não se resolviam 
nessa perspectiva e exigiam uma atenção maior para elementos pouco estáveis dos processos técnicos como são as percepções, valores, crenças e interesses neles presentes (JACKSON, 2002:211).

A abordagem funcionalista é abertamente positivista, e sua ênfase no lógos mostra como, desde há muito tempo, se desenvolve uma espécie de desequilíbrio epistemológico que leva necessariamente a entender a formação técnica dos engenheiros como uma formação de cunho científico e não como uma formação que desenvolva de maneira ampla várias outras características próprias do processo produtivo, como é o citado caso da inventividade e engenhosidade. Atualmente, os elementos presentes na inventividade técnica não se tornam aplicáveis de forma eficiente somente a partir da articulação de um conjunto de conhecimentos de base científica. É necessário também que tais elementos sejam articulados a partir de um leque amplo de competências necessárias para lidar, por exemplo, com a variabilidade e incerteza do mundo globalizado.

A métis reconfigura o pensamento sobre a engenharia porque coloca de volta a condição a instabilidade do devir no foco da formação do engenheiro. Nele, reposiciona o conhecimento científico sobre a sua própria base epistemológica deixando ao descoberto que também existem demandas por conhecimentos e competências para a inventividade, e, ainda que se reconheça nas Diretrizes a necessidade um perfil profissional criativo, a formação para a inventividade requer muito mais do que a enunciação dessa necessidade, pois nem mesmo o processo formativo atual tem dado garantias para atender tal desejo. Os engenheiros formam parte de um grupo social organizado e relevante, erguido sob um par institucional que envolve a Universidade e o Conselho Federal. Essa relação podersaber remete para uma lógica social que ajuda a consolidar o modelo econômico dominante sem grandes questionamentos. Há uma cultura profissional associada a um estilo de vida que usufrui das vantagens do sistema capitalista e que como contrapartida, prega a objetividade e praticidade como característica fundamental do seu quadro operativo. Porém, o silencio fase aos inúmeros problemas recorrentes da intervenção técnica na sociedade, o que se observa é a dificuldade na formação de uma subjetividade adequada ao perfil criativo do quadro normativo (ARAVENA-REYES, 2014b; LOPES, 2016). Portanto, não se trata só da enunciação de um papel social, senão da efetiva produção de uma subjetividade que possa dar condições de existência a esse novo e criativo engenheiro.

Dentro do marco das atuais demandas por desenvolvimento de competências para o mundo globalizado, a astúcia e a engenhosidade se revelam importantes em função de, atualmente, ser requerido um processo para formar profissionais criativos que também tenham competências para o trabalho em equipe. Em relação a formar profissionais criativos, a implicação de uma métis na formulação do solo epistemológico dos processos de ensino é direta: na medida em que se favoreça a inventividade técnica, na forma do desenvolvimento de uma zona plástica de acomodação entre o pensar/agir técnico e uma realidade variável ou imprevisível (um devir instável, móvel e ambíguo), os profissionais serão mais criativos.

Já no caso de desenvolver competências para o trabalho em equipes, a presença da métis parece menos evidente. A forma como se aborda (quando se aborda) o desenvolvimento de competências para o trabalho em equipes, geralmente é através do uso de metodologias de estudo e pesquisa em grupos ou de dinâmicas de grupo. Porém, pouca atenção é dada aos problemas que surgem 
das condutas imprevistas dos atos de fala oriundos das atividades colaborativas. Nesse caso, o tipo de solo epistemológico exige um entendimento amplo de como a técnica se configura no espaço das relações sociais. Este entendimento deveria estar articulado sobre as características presentes no próprio ato discursivo (a techné da retórica, da poética ou da política) que se estabelece no espaço de ação trans-individual. Tal abordagem permitiria contribuir efetivamente na dimensão psicossocial criada pelos membros de um coletivo (seja este profissional ou não) promovendo uma plasticidade discursiva e comportamental mais profunda, uma vez que ela opera no estrato linguístico e afetivo de um "saber dialogar". Desta forma, abordagens interpretativas ou que consideram como base o desenvolvimento de um saber dialogar dentro de uma realidade múltipla e variada (situação típica em equipes de trabalho), devem ser consideradas como eixos fundamentais para desenvolver as competências do trabalho em equipe, pois elas possuem elementos técnicos apropriados (a chamada métis) para lidar efetivamente com o tipo de situações encontradas na prática profissional.

Mas, não se trata de formar um engenheiro para só promover a manutenção do atual estado de coisas, pois notoriamente, o modelo dominante pode colocar a espécie humana em direção de um colapso econômico global (MARTENSON, 2011) ou mesmo da extinção planetária (VIVEIROS DE CASTRO \& DANOWSKY, 2014). O chamado Antropoceno (CRUTZEN, 2002) é um termo que serve tanto para descrever esta etapa geológica quanto para alertar o enorme poder destrutivo que acarreta inerentemente o atual modelo dominante. O lógos da invenção é de natureza diferente do lógos da inovação, pois este último está fortemente condicionado por relações externas à técnica (p.e. sistema econômico e estado), e aparentemente, é no processo inovador -e não no gesto inventivo-onde devem operar primeiros deslocamentos antropocênicos de cuidado com o planeta Terra.

Por tanto, trata-se da invenção tomando como base outras realidades, outros mundos, outros modos de existência; quer dizer, trata-se da invenção sob uma nova base epistemológica diferente da que norteia o processo de inovação, pois, mais do que participar do atual modelo de inovação industrial, é preciso promover novos modelos industriais, menos nocivos com o planeta, como sugere Stiegler (LEMMENS, 2011).

Sem dúvidas a métis é um tipo de inteligência que, se considerada no solo epistemológico da formação de engenharia, seria de extrema relevância não só para as competências citadas nos parágrafos anteriores, senão que para o desenvolvimento de diversas outras competências dos engenheiros. A dimensão da inventividade (técnica ou não) ou do pensamento astucioso, desenvolve competências apropriadas para lidar com as mais diversas e inusitadas (quer dizer, variáveis) situações para as quais ainda não há referencias exatas ou universais, e, talvez seja a falta de uma formação dessa natureza o que vêm provocando diversos mal-entendidos e críticas em relação ao papel dos engenheiros na produção técnica contemporânea, pois dita formação esta sujeita a uma epistemologia dominante ou minimamente redundante, que insiste formalmente num lógos, mas que relega aspectos do processo formativo a um espaço de poder pouco flexível que fundamenta a prática de uma formação atrelada, inclusive, a um processo de obediência para com a ideia de que a engenharia somente é resolução de problemas e não a invenção deles perante uma ampla realidade que exige constantemente processos de adaptação em relação à sua dinâmica cultural e produtiva (ARAVENA-REYES, 2014b). 
I// RBECT

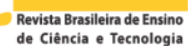

Página | 303 


\title{
Philosophy and Engineering Teaching: the Relation Techné, Lógos and Métis.
}

\begin{abstract}
This paper presents a study on certain etymological antecedents that underlie a relevant epistemological ground for teaching engineering. For this aim, it is presented an articulation between the Greeks terms techné, lógos and métis to argue that the current teaching process of engineers emphasizes more on sciences while devotes little effort to develop the inventive thought, a key element for the development of skills for the engineers' creative process.
\end{abstract}

KEYWORDS: Philosophy of engineering. Philosophy of technology. Engineering education. Invention. Métis. 
1 Entre as contribuições para a formação do "novo engenheiro" se encontram: o uso de estruturas flexíveis, a articulação com o campo profissional, uma abordagem pedagógica centrada no aluno; o uso de um enfoque multidisciplinar, a valorização do ser humano, a preservação do meio ambiente, a integração social e politica do engenheiro e um claro entendimento de currículo como conjunto de experiências de aprendizado e não de "grade" de disciplinas.

2 Para um resumo histórico desse processo de construção social, consultar as seções 3.4 a 3.7 da tese de doutorado desenvolvida por Nascimento (2008).

3 O termo macropolítica é usado aqui no contexto dos trabalhos de Gilles Deleuze e Felix Guattari apresentados no capítulo Micropolítica e Segmentaridade do livro Mil Platôs (2010).

4 Para conhecer o estado da arte dessa perspectiva pode ser consultada a recente publicação Philosophy of Technology after the Empirical Turn editada por M. Franssen et al (2016).

5 Ver o site da sociedade em http://www.spt.org/ e o site da sua revista de divulgação científica Techné em http://www.spt.org/techne/

6 No texto das diretrizes a tecnologia aparece associada à formação técnico científica (que "o capacite a absorver e desenvolver novas tecnologias") e como uma habilidade a ser desenvolvida ("aplicar conhecimentos matemáticos, científicos, tecnológicos...").

7 É interessante notar que tanto a seção dedicada à filosofia da tecnologia na Introdução aos Estudos CTS da Organização de Estados Ibero-americanos (Bazzo et al, 2003), quanto o texto introdutório da Filosofia da Tecnologia de Antonio Lopez Cerezo (Cerezo \& Julán, 1998) seguem o roteiro desenvolvido por Mitcham na sua primeira grande obra sobre filosofia da tecnologia (1989).

8 Mitcham é relevante nos estudos filosóficos da engenharia porque em seus trabalhos há um espaço muito importante ao que ele denomina de "tradição engenheiril da filosofia da tecnologia".

9 O solo epistemológico que, por exemplo, permite gerar o entendimento dominante de que a engenharia trata de resolução (e não da invenção) de problemas (ARAVENA-REYES, 2014a)

10 Ver, por exemplo, a análise feita por Simondon (2009) em torno da evolução da técnica ou a discussão de Stiegler (2003: 59-62) sobre invenção e inovação.

\section{REFERÊNCIAS}

ARAVENA-REYES, J.; A problematização como invenção: Fundamentos para a Educação em Engenharia, Revista de Ensino em Engenharia, Vol. 33, No. 2, Brasil, 2014a.

ARAVENA-REYES, J.; For a Micro-Politics Analysis of Engineering Education, 
ARAVENA-REYES, J.; O Conceito de Engenharia à Luz do Conselho Profissional: Por uma Crítica Filosófica do Ensino de Engenharia, Revista Engenharia Viva, v. 2. 2015, Goiânia, Brasil, págs. 31-46.

ARISTÓTELES; Retórica, Trads. Manuel Alexandre Junior, Paulo Farmhouse Alberto e Abel do Nascimento Pena, Edições Profissionais Ltda., São Paulo, Brasil, 2012.

ARISTÓTELES; Ética a Nicômano, 3ạ Edição, 1a Reimpressão, Trad. Edson Bini, Edições Profissionais Ltda., São Paulo, Brasil, 2013.

ARISTÓTELES; Metafísica, 2a Edição, 1a Reimpressão, Trad. Edson Bini, Edições Profissionais Ltda., São Paulo, Brasil, 2015.

BAZZO, W. \& PEREIRA, L.; Introdução à Engenharia, Editora da UFSC, 6ạ Edição, 2002, Brasil.

BAZZO, W. et al (Ed). Introdução aos Estudos CTS (Ciência, Tecnologia e Sociedade), Organização dos Estados Ibero-americanos para a Educação, a Ciência e a Cultura (OEI), Espanha, 2003.

BIJKER, W. \& LAW, J.; Shaping Technology - Building Society: Studies in Sociotechnical Change, MIT Press, Camgridge, 1992.

CEREZO, J. \& JULÁN, J., Filosofia de la Tecnologia: Presentación, Teorema Revista Internacional de Filosofia, Vol XVII-3, Universidad de Oviedo, Espanha, 1998, págs. 5-10.

CHAUI, M.; Introdução à História da Filosofia: Dos pré-socráticos a Aristóteles, Vol. I, Companhia das Letras, 2002, São Paulo, Brasil.

CORDEIRO, J. QUEIRÓS, P. \& BORGES, M.; A Associação Brasileira de Educação em Engenharia (Abenge) em Trajetória e Estado da Arte da Formação em Engenharia, Arquitetura e Agronomia, v. I: Engenharias, INEP-CONFEA, Brasília, Brasil, págs. 119-128, 2010.

CRUTZEN, P.; Geology of Mankind; Nature, Vol. 45, No. 3, MacMillan Publishers Limited, 2002, Pág. 23.

DELEUZE, G. \& GUATTARI, F.; Mil mesetas: Capitalismo y Esquizofrenia, 10a 
DETIENNE, M \& VERNANT, J.; Métis: As astúcias da Inteligência, Trad. Filomena Hirata, Odysseus Editora Ltda., Brasil, 2008.

DINUCCI, A. \& JULIEN, A.; O Encheirídion de Epitecto, Edição Bilingue, Trad. Aldo Dinucci e Alfredo Julien, Editora da Universidade Federal de Sergipe, Editorial Prometeus, São Cristovão, Brasil, 2012.

DURBIN, P.; An Introductory Essay: A Framework for Understanding

Philosophical Controversies, em Techné: Research in Philosophy and Technology, Vol. 10, pág. 4-14, $2006 a$.

DURBIN, P.; Chapter 1: A Premature Attempt at Discourse Synthesis: Carl Mitcham in Thinking through Technology, em Techné: Research in Philosophy and Technology, Vol. 10, pág. 16-26, 2006b.

DURBIN, P.; Chapter 15: Philosophy of Engineering, em Techné: Research in Philosophy and Technology, Vol. 10, pag. 141-151, 2006c.

ÉSQUILO; Prometeu Acorrentado, Trad. J. B. de Melo e Souza, E-Book Brasil, Versão digital de Clássicos Jackson, Vol. XXII, Editora M. W. Jackson, Brasil, 2005.

FRANSSEN et al.; Philosophy of Technology after the Empirical Turn, Philosophy of Engineering and Technology Series, v. 23, Springer, 2016.

FEENBERG, A.; Critical Theory of Technology, Oxford University Press, New York, 1991.

FEENBERG, A.; Transforming Technology: A Critical Theory Revisited, Oxford University Press, New York, 2002.

GALIMBERTI, U.; Psiche e Techné: O homem na idade da técnica, Trad. José Maria de Almeida, Editora Paulus, Brasil, 2006.

HESÍODO, Teogonia; Trad. Ana Lúcia Silveira Cerqueira e Maria Therezinha Arêas Lyra, 2a Edição, Editora da Universidade Federal Fluminense, Rio de Janeiro, Brasil, 1996.

JACKSON, M.; Systems Approaches to Management, Kluwer Academic Publishers, London, UK, 2002. 
KROES, P. \& MEIJERS, A.; The Empirical Turn in the Philosophy of Technology, Research in Philosophy and Technology, v. 20, Elsevier Science, Amsterdam, 2001.

LEMMENS, P.; This System Does Not Produce Pleasure Anymore: An Interview With Bernard Stiegler, Krisis: Journal for Contemporary Philosophy, Issue 1, 2011, Holanda.

LOPES, M.; Qual Engenheiro? - Uma análise dos Projetos Político-Pedagógicos dos Cursos de Engenharia da Universidade Tecnológica Federal do Paraná (UFPR) em Revista de Ensino de Engenharia, v. 25. No. 1, Brasil, 2016, págs. 2333.

MARTENSON, C.; The Crash Course: The Unsustainable Future Of Our Economy, Energy, And Environment, Willey and Son Inc., USA, 2011.

MEC; Parecer CNE/CES 1.362/2001: Diretrizes Curriculares Nacionais dos Cursos de Engenharia, Disponível em http://www.utfpr.edu.br/estruturauniversitaria/pro-reitorias/prograd/legislação/ arquivos/bacharelado/direngcneces13622002.pdf, Brasília, Brasil, 2001.

MEC; Resolução CNE/CES 11/2002: Institui Diretrizes Curriculares Nacionais do Curso de Graduação em Engenharia, Disponível Em http://portal.mec.gov.br/cne/arquivos/pdf/ CES112002.pdf, Brasília, Brasil, 2002.

MEIJERS, A.; Philosophy of Technology and Engineering Sciences, Handbook of the Philosophy of Science, Vol. 9, Elsevier V. B., Oxford, USA, 2009.

MITCHAM, C. Qué es la Filosofía de la Tecnología?, Trad. Cesar Cuello Nieto e Roberto Mendez Stingl, Editorial Antrophos e Servicio Editorial de la Universidad del Pais Vasco, Coleção Nueva Ciencia, Barcelona, Espanha, 1989.

MITCHAM, C. Thinking Through Technology: The path between Engineering and Philosophy, Trad. Cesar Cuello Nieto e Roberto Mendez Stingl, The University of Chicago Press, Chicago, USA, 1994. Internacional de Filosofia, Vol XVII-3, Universidad de Oviedo, Espanha, Pág. 27-47, 1998. 
MITCHAM, C. \& SCHATZBERG, E.; Defining Technology and the Engineering Science, Philosophy of Technology and Engineering Sciences, A. Meijer Ed., Handbook of the Philosophy of Science, Vol. 9, Elsevier V. B., Oxford, USA, pág. 27-64, 2009.

NASCIMENTO, Z.; Formação e Inserção de Engenheiros na Atual Fase de Acumulação do Capital: O caso Tupy-Sociesc (Tese de Doutorado), Universidade Federal do Paraná, Curitiba, 2008.

NIETZSCHE, F.; Crepúsculo dos Ídolos - ou como filosofar com o martelo. Trad. Marco Antonio Casa Nova. Relume Dumará, Rio de janeiro, Brasil, 2000.

PINTO, D., OLIVEIRA, V.; Reflexões sobre a prática do engenheiro-professor. Anais do XL Congresso Brasileiro de Educação em Engenharia, COBENGE, Belém, PA, 2012.

SILVA, E.; Filosofia da engenharia: $O$ que é e porque deveria se interessar, Dissertação de Mestrado, COPPE UFRJ, Rio de Janeiro, Brasil, 2011.

SIMONDON, G.; El Modo de Existencia de los Objetos Técnicos, Trad. Pablo Ires, Editorial Cactus e La Cebra Editores, Buenos Aires, 2009.

STIEGLERS, B.; La Técnica y el Tiempo I: El Pecado de Epimeteo, Trad. Beatriz Morales Bastos, Colección Pensar, Cultura Libre, HIRU, Espanha, 2003.

VERNANT, J.; Mito e Religião na Grécia Antiga, Trad. Joana Angélica D’Avila Melo, Livraria Martins Fontes Editora Ltda., Brasil, 2006.

VIVEROS DE CASTRO, E. \& DANOWSKI, D.; Há Mundo por Vir? Ensaio sobre os Medos e os Fins, Instituto SocioAmbiental, Cultura e Barbarie Editora, Florianopolis, Brasil, 2014.

WINNER, L.; Autonomous Technology: Technics-out-of-Control as a Theme in Political Thought, The MIT Press, Cambridge, 1977. 
Recebido: 12 mai. 2015

Aprovado: $07 \mathrm{fev} .2017$

DOI: $10.3895 /$ rbect.v9n3.2950

Como citar:

ARAVENA-REYES, J. Filosofia e Ensino de Engenharia: a Relação Techné, Lógos e Métis. Revista

Brasileira de Ensino de Ciência e Tecnologia, v. 9, n. 3, 2016. Disponível em:

<https://periodicos.utfpr.edu.br/rbect/article/view/2950>. Acesso em: xxx.

Correspondência:

José Aravena-Reyes

Departamento de Construção Civil, Faculdade de Engenharia, Universidade Federal de Juiz de Fora, Rua José Lourenço Kelmer s/n, Martelos, 205, 36036-330 - Juiz de Fora - Minas Gerais

Direito autoral: Este artigo está licenciado sob os termos da Licença Creative Commons-Atribuição 4.0 Internacional. 